\title{
Pathophysiology of Status Epilepticus
}

Matthew C Walker ${ }^{1}$

${ }^{1}$ Department of Clinical and Experimental Epilepsy, UCL Institute of Neurology, London WC1N 3BG

Keywords: status epilepticus; drug resistance; reactive oxygen species;

mitochondria; excitotoxicity

Corresponding Author:

Department of Clinical and Experimental Epilepsy, UCL Institute of Neurology, London WC1N 3BG, UK Tel: +44(0)2034484194 email: m.walker@ucl.ac.uk 


\section{Abstract}

Status epilepticus (SE) is the maximal expression of epilepsy with a high morbidity and mortality. It occurs due to the failure of mechanisms that terminate seizures. Both human and animal data indicate that the longer a seizure lasts, the less likely it is to stop. Recent evidence suggests that there is a critical transition from an ictal to a post-ictal state, associated with a transition from a spatio-temporally desynchronized state to a highly synchronized state, respectively. As SE continues, it becomes progressively resistant to drugs, in particular benzodiazepines due partly to NMDA receptor-dependent internalization of GABA(A) receptors. Moreover, excessive calcium entry into neurons through excessive NMDA receptor activation results in activation of nitric oxide synthase, calpains, and NADPH oxidase. The latter enzyme plays a critical part in the generation of seizuredependent reactive oxygen species. Calcium also accumulates in mitochondria resulting in mitochondrial failure (decreased ATP production), and opening of the mitochondrial permeability transition pore. Together these changes result in status epilepticus-dependent neuronal death via several pathways. Multiple downstream mechanisms including inflammation, break down of the blood-brain barrier, and changes in gene expression can contribute to later pathological processes including chronic epilepsy and cognitive decline. 


\section{Introduction}

Although most seizures last a brief time (secondarily generalized seizures last less than 2 minutes[1]), occasionally seizures can become more prolonged, and are then considered as a separate entity - status epilepticus (SE) - because of the associated high morbidity and mortality[2,3]. It has long been recognized that the hippocampus is particularly vulnerable to damage by prolonged seizures[4]. In 1880, Pfleger described hemorrhagic lesions in the mesial temporal lobe of a patient dying in status epilepticus, and he concluded that neuronal necrosis was the result of impaired blood flow or metabolic disturbances that occurred during the seizures[5]. More recently, postmortem studies have revealed significant acute neuronal loss in the hippocampi of patients dying in convulsive status epilepticus and MRI studies have also shown progressive atrophy of the hippocampus in people following status epilepticus[6,7]. With prolonged refractory status epilepticus, general brain atrophy has been found, although it is not clear whether this was the result of the SE or the treatment, in particular prolonged general anesthesia [8]. A recent postmortem study of unselected patients demonstrated that there are patients who have had episodes of status epilepticus with no evidence of damage in the hippocampus, suggesting that status epilepticus alone may not be sufficient to cause neuronal damage[9].

The long-standing definition of status epilepticus was a seizure that lasted longer than 30 minutes, but this definition lacks clinical utility[10]. In addition, a greater understanding of the pathophysiology of status epilepticus has led to a redefinition of status epilepticus[11]. This definition recognizes that status epilepticus can be defined by two distinct pathophysiological processes - those that lead to prolongation of the seizure and those that lead to its pathophysiological consequences. As I will discuss below, these processes are not necessarily mutually exclusive. The new definition [11] is: "SE is a condition resulting either from the failure of the mechanisms responsible for seizure termination or from the initiation of mechanisms which lead to abnormally prolonged seizures (after time point $\mathrm{t} 1$ ). It is a condition that can have long-term consequences (after time point t2), including neuronal death, neuronal injury, and alteration of neuronal networks, depending on the type and duration of seizures."

Status epilepticus is not uncommon affecting 10-41 per 100,000 per year[12]. Approximately $4-16 \%$ of people with epilepsy will have at least one episode of status epilepticus[13], and approximately half the episodes of status epilepticus occur in people with no prior history of epilepsy[14]. Status epilepticus has a mortality of $10-$ $20 \%$, although recent data indicates that more rapid treatment regimens that have been instigated in the $21^{\text {st }}$ century have resulted in a fall in mortality[15,16]. In 
addition, those that survive status epilepticus have associated cognitive and neurological deficits, and importantly status epilepticus is a risk factor in those without epilepsy for the development of chronic epilepsy[17]. Acute symptomatic status epilepticus has a three-fold risk of resulting in chronic epilepsy compared to acute symptomatic seizures[17]. Status epilepticus, importantly, can be caused by a range of etiologies (Fig. 1) [14], and etiology is often the main determinant of prognosis[18]. Here, I will consider three clinically relevant aspects to the pathophysiology of status epilepticus: why seizures persist, how prolonged seizures become drug resistant and lastly the mechanisms underlying neuronal death and those that may eventually drive cognitive decline and the increased risk of epilepsy.

\section{Why do seizures persist?}

\subsection{Termination of seizures}

A host of different biological processes have been proposed to lead to seizure termination including neurotransmitter depletion, ATP depletion, ionic changes, acidosis, increased GABAergic drive, release of adenosine, and release of peptides[19]; suppression or failure of these processes may promote status epilepticus. Moreover, there may be pro-seizure processes occurring during the development of status epilepticus including breakdown of the blood-brain barrier, inflammation, and increased expression of pro-epileptogenic peptides[20,21]. Furthermore, it has been observed that spatial and temporal synchronization occur before seizure and status epilepticus termination[22]. Indeed, effective treatment of status epilepticus seems to promote spatial synchronization prior to status epilepticus termination. This has led to a further examination of seizure dynamics prior to seizure termination, which found increased spatial and temporal synchronization, slowing of the frequency of mean power and flickering (fluctuations between ictal and post-ictal EEG variance values, measured over small, $50 \mathrm{~ms}$, intervals)[23]. These observations have led to the concept that there is a critical transition from an ictal to a post-ictal state (Fig. 2).

\subsection{Nature of status epilepticus}

Status epilepticus can then be viewed as a failure to cross that transition. Status epilepticus can be considered as repetitive approaching and then retreating from the critical transition. This results in a decrease in the frequency of mean power and an increase in autocorrelation followed by the converse[23]. Such variation may explain the cyclical nature of the EEG and clinical manifestations of status epilepticus that have been described[24]. From a biological perspective, this can be viewed as a 
failure of processes that "push" the seizure towards the post-ictal state. "Reinforcing" these processes with medication, eg by increasing GABAergic inhibition can therefore drive the brain state towards the post-ictal state.

The animal models of de novo status epilepticus give us some insight into the progression towards status epilepticus. What is required in these models is something that drives persistent seizure activity. Stimulation protocols in which seizure activity is "driven" for more than 30 minutes becomes self-perpetuating ie once the stimulation is stopped self-sustaining status epilepticus continues; indeed, the longer the stimulation, the greater the chance of self-sustained status epilepticus (Fig. 3) $[25,26]$. This points to an exhaustion of those processes necessary for seizure termination and/or a strengthening of those processes that drive seizure activity. In most animal models, status-epilepticus can then be suppressed or terminated with drugs; anesthetic doses may be necessary. Status epilepticus can, however, then recur, which may contribute to the pathophysiological outcome, but nevertheless the status epilepticus eventually resolves [27].

\subsection{Nature of refractory status epilepticus}

Human observation tells an even more complex story. It has certainly been observed that the longer a seizure continues, the less likely it is to stop[28-30]; this is consistent with the concept that seizure activity itself can exhaust seizure inhibitory mechanisms (or strengthen seizure-promoting processes). Most people with status epilepticus have their status epilepticus stopped with initial therapy or even with second- or third-line therapies. This is consistent with the two-state model and a failure of crossing the transition (Fig. 2). However, there are a proportion that go on to super-refractory status epilepticus, "status epilepticus that continues or recurs 24 hours or more after the onset of anesthetic therapy, including those cases where status epilepticus recurs on the reduction or withdrawal of anesthesia"[31]. The existence of super-refractory status epilepticus indicates that in some cases the postictal state does not exist as a stable state and so once the anesthesia is removed the brain reverts to the ictal state. In my opinion, there are two main reasons why this may be so and these different reasons point to distinct therapeutic approaches (Fig. 2). First, there may be an ongoing pathological process (eg infection or autoimmune disease) that drives the brain back into seizure activity. This can be addressed by treating the underlying pathological process, or stopping seizure activity with anesthesia until the underlying etiology has resolved. Second, the underlying pathology and/or the status epilepticus has resulted in changes to the brain that make the post-ictal state intrinsically unstable. This latter process could be the result 
of permanent or semi-permanent changes such as neuronal death (in particular the death of interneurons), inflammation, break down of the blood-brain barrier, altered network connectivity, altered receptor/ion channel expression and altered neurotransmitter release. The treatment approach here is more complex, and there is no clear guidance from clinical or pre-clinical studies. The addition of multiple medications may make the post-ictal state more stable. There may be other ways of altering the stability of the post-ictal state including surgery, and brain stimulation. Following SE, EEG patterns that suggest an unstable state such as periodic lateralized epileptiform discharges, burst suppression patterns, or "after SE ictal discharges" (ASIDs) defined as ictal EEG activity lasting at least 10 seconds to a few minutes that starts and stops abruptly, and which is not associated with a clinical change, are associated with a high mortality $(40-60 \%$ within 30 days of the cessation of status epilepticus)[32].

\section{Drug resistance and acute receptor changes}

An observation in animal models is that the longer status epilepticus continues the harder it is to treat[33-35]. One explanation can immediately be appreciated from the section above. If there are biological processes that "push" the brain from an ictal to a post-ictal state, then as these become exhausted or as the processes that drive the brain into an ictal state become strengthened so any treatment will necessarily have to have a larger effect. This is the concept of "worse disease needs stronger treatments."

\subsection{Changes in $\operatorname{GABA}(\mathrm{A})$ receptors}

There are, however, other more specific biological processes at play. It has long been recognized that benzodiazepines lose their potency as status epilepticus continues and that this is partly due to the internalization of synaptic (gammasubunit) containing $\mathrm{GABA}(\mathrm{A})$ receptors[35-37]. This involves the activation of NMDA receptors and then calcineurin-dependent internalization of the $\operatorname{GABA}(A)$ receptors[38,39]. This process points to three specific treatment approaches. First, inhibition of NMDA receptor may increase the potency of benzodiazepines; this has been observed in animal models of status epilepticus[40-42]. Second, calcineurin antagonists would be predicted to have the same effect. Lastly, therapeutic strategies that target the extrasynaptic (gamma-subunit lacking) $G A B A(A)$ receptors should be more effective late-on in status epilepticus. Anesthetics and in particular, neurosteroids, target these extrasynaptic $\operatorname{GABA}(\mathrm{A})$ receptors and have been shown to be effective in benzodiazepine-resistant status epilepticus[43-45]. Lastly, the 
resistance to GABAergic drugs may not be solely the result of changes in receptors but also in the phosphorylation state of the potassium-chloride transporter, KCC2, resulting in KCC2 internalization, elevated levels of intracellular chloride and consequent decreased inhibitory efficacy of $\operatorname{GABA}(\mathrm{A})$ receptor activation[46].

\subsection{Other changes}

This process of acute receptor changes is not restricted to $\operatorname{GABA}(A)$ receptors. NMDA receptor expression increases in excitatory cells, presynaptic adenosine $A 1$ receptor and $\mathrm{GABA}(\mathrm{B})$ receptor expression is decreased, and AMPA receptors lose their GluA2 subunit[25,47-49]. GluA2-lacking AMPA receptors are calcium permeable and may contribute to calcium accumulation, possibly leading to neuronal death[48]. These findings indicate a role for glutamate receptor antagonists in status epilepticus, and, in particular, NMDA receptor antagonists as a means of modifying the condition (possibly preventing drug resistance).

It is not only changes in receptors that could have an impact on drug sensitivity but also the increased aberrant expression of drug transporter proteins in response to status epilepticus that may promote resistance to certain antiepileptic drugs[50]. A recent study, however, found no impact of genetic knockout of p-glycoprotein on the response of status epilepticus induced by intrahippocampal kainic acid to antiepileptic drugs and there was no upregulation of P-gycoprotein in this model[51]. This study indicates that P-glycoprotein is not involved in the mechanisms explaining drug resistance in this model of focal status epilepticus, but does not exclude a role for other drug transporters or a role in other models of $S E[51]$.

\section{Neuronal death and dysfunction}

\subsection{Neuronal death and calcium}

A myriad of changes occurs in the days and weeks following status epilepticus. Many of these are driven by changes in gene expression due to changes in transcription factors, microRNA expression and DNA methylation. I will, here, confine myself to some of the more acute changes that occur in status epilepticus that have a direct bearing on the acute pathophysiology.

The most obvious impact of status epilepticus is neuronal death. Specific groups of neurons seem to be more susceptible and neuronal death is usually more obvious in the hippocampus, in particular in the hilus, CA3 and CA1 regions - the precise 
spatial and temporal pattern in animal models seems to be model, strain and age dependent[52-54].

Prolonged convulsive seizures can lead to physiological compromise including hypotension, hypoxia and acidosis that contribute to neuronal damage. However, seminal experiments by Meldrum and colleagues in baboons in the 1970's demonstrated that seizure activity, itself, can cause neuronal damage[55,56]. This neuronal damage is dependent upon calcium entry and accumulation in neurons[57]. NMDA receptors are key in this process. Inhibition of NMDA receptors or calcium entry through NMDA receptors is neuroprotective in vitro[58-60] and in vivo[61,62]. $\mathrm{Ca}^{2+}$ permeable AMPA receptors may also play a role[48]. During the development of status epilepticus and as a result of neuronal death, ATP is released into the extracellular fluid and can activate P2X receptors, which may also permit calcium entry into neurons and glia and may play a role in neuro-inflammation and neuronal death[63].

\subsection{Enzymes activated by intracellular calcium accumulation}

The downstream mechanisms from calcium entry and accumulation are less clear. Calcium entry can activate several enzymes that have been implicated in neuronal death. Although apoptosis through activation of caspase 3 has been proposed to be a major pathway leading to neuronal death following status epilepticus[64], more recent evidence suggests that this pathway plays no or only a minor role[65,66]. Other enzymes that have been implicated include the calpains - calcium-dependent, non-lysosomal cysteine proteases [67]. Members of the calpain family, however, have different targets and their activation results in a complex array of protein degradation with calpain 1 activation having predominantly neuroprotective effects whilst calpain 2 activation is neurotoxic $[68,69]$. These calpains may be activated to different degrees in different neuronal subtypes, perhaps explaining patterns of neuronal death in status epilepticus[69]. Nitric oxide synthase (NOS) is also activated by calcium entry through NMDA receptors. NOS exists as three different isoforms: neuronal NOS and endothelial NOS, which are both activated through cellular calcium entry, and inducible NOS, which is constantly active and not regulated by intracellular calcium concentrations[70]. Inducible NOS is mainly present in inflammatory cells, and inhibition of this may reduce inflammation and neuroprotect following status epilepticus [71]. Nitric oxide, which usually plays an important physiological role, when overproduced can combine with reactive oxygen species (see below) to produce peroyxnitrite, which at high concentrations is neurotoxic resulting in DNA injury, lipid peroxidation, impairment of cellular signaling, and 
mitochondrial dysfunction [72,73]. However, in status epilepticus, nitric oxide may play a more important role in neuronal damage through increasing calcium release from internal stores through activation of ryanodine receptors[74].

\subsection{Mitochondrial dysfunction}

Perhaps one of the main routes from calcium entry to neuronal dysfunction and death is through mitochondrial dysfunction. Mitochondria are one of the main buffers of cytosolic calcium, taking up calcium predominantly through the mitochondrial calcium uniporter[75]. Calcium uptake by mitochondria activates mitochondrial respiratory chain function and can increase mitochondrial ATP (and free radical) production through activation of calcium-dependent NADH dehydrogenases[75]. However, excessive mitochondrial calcium accumulation has two main detrimental effects. First, calcium accumulation can result in mitochondrial membrane depolarization[60]. Since the mitochondrial membrane potential is necessary for ATP production, this can result in decreased ATP production and consequently cellular energy failure[60]. Energy failure results in a decrease in the cell's ability to maintain ionic gradients, and so results in cellular depolarization, hyperexcitability and eventually cell death. Increasing ATP production during seizure activity by providing substrate, such as pyruvate, for mitochondria can prevent neuronal death[60,76]. Second, excessive calcium and reactive oxygen species production can result in opening of the mitochondrial permeability transition pore (mPTP). The mPTP is permeable to pro-apoptotic proteins such as cytochrome c[77]. mPTP opening also leads to further depolarization of the mitochondrial membrane potential with a consequent decrease in ATP production, disordered ionic homeostasis and mitochondrial matrix swelling.

\subsection{Reactive oxygen species}

Another major consequence of intracellular calcium accumulation and excessive activation of NMDA receptors is the overproduction of reactive oxygen species. Mitochondrial calcium accumulation can result in increased mitochondrial reactive oxygen species (ROS) production[78]. ROS can further contribute to MPTP opening through release of internal calcium stores via activation of ryanodine receptors and inhibition of sarcoplasmic reticulum calcium-ATPase[78]. Although ROS production during prolonged seizure activity was attributed to mitochondria[79], more recent evidence suggests that seizure-activity results in mitochondrial failure with reduced mitochondrial ROS production[80]. Seizure-induced ROS is probably generated through NMDA receptor-dependent, calcium-independent activation of NADPH 
oxidase[80,81]. Then, later ATP depletion results in adenine formation and an increase in hypoxanthine and xanthine, substrates for xanthine oxidase, which also generates ROS[80]. NADPH oxidase activity is increased during seizure-activity[81]. Inhibition of NADPH oxidase can neuroprotect in in vivo models of status epilepticus[82-84]. As previously described ROS and consequent peroxynitrite formation can contribute to cell death though lipid peroxidation, inactivation of enzymes, mPTP opening and DNA damage. Moreover, ROS can directly inhibit mitochondrial complex 1 activity, further impeding ATP production[85,86]. ROS induced DNA damage can lead to activation of poly (ADP-ribose) polymerase (PARP), a repair enzyme. Excessive PARP activation can further lead to rapid ATP depletion which can also stimulate cascades leading to cell death[87].

Overall, it is likely that mitochondrial failure and excessive ROS production are the main pathways leading to the acute SE-induced pathology (Fig. 4). Importantly targeting these acute mechanisms may prevent downstream consequences, but it is likely that these need to be targeted early in the condition. With time, calcium accumulation, neuronal death, ROS production, and ATP depletion will activate other pathways, and additional downstream mechanisms likely contribute to the longerterm consequences of status epilepticus, including chronic epilepsy and cognitive problems.

\section{Conclusion and future perspectives}

Our understanding of status epilepticus is burgeoning on several fronts. We are beginning to understand better the mechanisms that lead to the failure of termination of seizure activity, and those that lead to resistance to drug therapy. Continued progress is also being made in determining the mechanisms leading to status epilepticus-induced neuronal death. However, the relative importance of a variety of downstream mechanisms that result in the later consequences of status epilepticus including chronic epilepsy and cognitive decline is still unclear, and it is possible that under differing circumstances, the role of individual processes may vary. This suggests that either biomarkers will be necessary to direct the most appropriate therapy or polytherapy targeting a range of mechanisms will be necessary to prevent the many consequences of status epilepticus.

Acknowledgements: I would like to thank Epilepsy Research UK, and the European Commission (FP7 602102 EPITARGET) for supporting this work. Part of this work was undertaken at UCLH/UCL which receives a proportion of funding from the Department of Health's NIHR Biomedical Research Centers funding scheme. 


\section{References}

[1] W.H. Theodore, R.J. Porter, P. Albert, K. Kelley, E. Bromfield, O. Devinsky, S. Sato, The secondarily generalized tonic-clonic seizure: a videotape analysis., Neurology. 44 (1994) 1403-7.

[2] D.M. Treiman, M.C. Walker, Treatment of seizure emergencies: convulsive and non-convulsive status epilepticus., Epilepsy Res. 68 Suppl 1 (2006) S7782. doi:10.1016/j.eplepsyres.2005.07.020.

[3] J.W.Y. Chen, C.G. Wasterlain, Status epilepticus: pathophysiology and management in adults., Lancet Neurol. 5 (2006) 246-56. doi:10.1016/S14744422(06)70374-X.

[4] F. Kersanté, S.C.S. Rowley, I. Pavlov, M. Gutièrrez-Mecinas, A. Semyanov, J.M.H.M. Reul, M.C. Walker, A.C.E. Linthorst, A functional role for both aminobutyric acid (GABA) transporter-1 and GABA transporter-3 in the modulation of extracellular GABA and GABAergic tonic conductances in the rat hippocampus., J. Physiol. 591 (2013) 2429-41. doi:10.1113/jphysiol.2012.246298.

[5] L. Pfleger, Beobachtungen uber schrumpfung und Sclerose des Ammonshornes bei Epilepsie., Allg. Zeitschrift Für Psychiatr. 36 (1880) 359365.

[6] C.M. DeGiorgio, U. Tomiyasu, P.S. Gott, D.M. Treiman, Hippocampal pyramidal cell loss in human status epilepticus., Epilepsia. 33 23-7. http://www.ncbi.nlm.nih.gov/pubmed/1733757 (accessed February 23, 2015).

[7] P.M. Vespa, D.L. McArthur, Y. Xu, M. Eliseo, M. Etchepare, I. Dinov, J. Alger, T.P. Glenn, D. Hovda, Nonconvulsive seizures after traumatic brain injury are associated with hippocampal atrophy., Neurology. 75 (2010) 792-8. doi:10.1212/WNL.0b013e3181f07334.

[8] S. Hocker, E. Nagarajan, A.A. Rabinstein, D. Hanson, J.W. Britton, Progressive Brain Atrophy in Super-refractory Status Epilepticus., JAMA Neurol. 73 (2016) 1201-1207. doi:10.1001/jamaneurol.2016.1572.

[9] M. Thom, J. Zhou, L. Martinian, S. Sisodiya, Quantitative post-mortem study of the hippocampus in chronic epilepsy: seizures do not inevitably cause neuronal loss., Brain. 128 (2005) 1344-57. doi:10.1093/brain/awh475.

[10] D.H. Lowenstein, T. Bleck, R.L. Macdonald, It's time to revise the definition of status epilepticus., Epilepsia. 40 (1999) 120-2. http://www.ncbi.nlm.nih.gov/pubmed/9924914 (accessed October 15, 2015).

[11] E. Trinka, H. Cock, D. Hesdorffer, A.O. Rossetti, I.E. Scheffer, S. Shinnar, S. 
Shorvon, D.H. Lowenstein, A definition and classification of status epilepticus Report of the ILAE Task Force on Classification of Status Epilepticus., Epilepsia. 56 (2015) 1515-23. doi:10.1111/epi.13121.

[12] M.C. Walker, The epidemiology and management of status epilepticus., Curr. Opin. Neurol. 11 (1998) 149-54.

http://www.ncbi.nlm.nih.gov/pubmed/9551296 (accessed July 1, 2012).

[13] W.A. Hauser, Status epilepticus: epidemiologic considerations., Neurology. 40 (1990) 9-13. http://www.ncbi.nlm.nih.gov/pubmed/2185441 (accessed October 15, 2015).

[14] R.J. DeLorenzo, W.A. Hauser, A.R. Towne, J.G. Boggs, J.M. Pellock, L. Penberthy, L. Garnett, C.A. Fortner, D. Ko, A prospective, population-based epidemiologic study of status epilepticus in Richmond, Virginia., Neurology. 46 (1996) 1029-35. http://www.ncbi.nlm.nih.gov/pubmed/8780085 (accessed April 13, 2012).

[15] A. Neligan, S.D. Shorvon, Prognostic factors, morbidity and mortality in tonicclonic status epilepticus: a review., Epilepsy Res. 93 (2011) 1-10. doi:10.1016/j.eplepsyres.2010.09.003.

[16] A. Neligan, M.C. Walker, Falling status epilepticus mortality rates in England and Wales: 2001-2013?, Epilepsia. 57 (2016) e121-4. doi:10.1111/epi.13402.

[17] D.C. Hesdorffer, G. Logroscino, G. Cascino, J.F. Annegers, W.A. Hauser, Risk of unprovoked seizure after acute symptomatic seizure: effect of status epilepticus., Ann. Neurol. 44 (1998) 908-12. doi:10.1002/ana.410440609.

[18] A.O. Rossetti, S. Hurwitz, G. Logroscino, E.B. Bromfield, Prognosis of status epilepticus: role of aetiology, age, and consciousness impairment at presentation., J. Neurol. Neurosurg. Psychiatry. 77 (2006) 611-5. doi:10.1136/jnnp.2005.080887.

[19] F.A. Lado, S.L. Moshé, How do seizures stop?, Epilepsia. 49 (2008) 16511664. doi:10.1111/j.1528-1167.2008.01669.x.

[20] D. Janigro, P.H. Iffland, N. Marchi, T. Granata, A role for inflammation in status epilepticus is revealed by a review of current therapeutic approaches., Epilepsia. 54 Suppl 6 (2013) 30-2. doi:10.1111/epi.12271.

[21] H. Liu, A.M. Mazarati, H. Katsumori, R. Sankar, C.G. Wasterlain, Substance P is expressed in hippocampal principal neurons during status epilepticus and plays a critical role in the maintenance of status epilepticus., Proc. Natl. Acad. Sci. U. S. A. 96 (1999) 5286-91.

[22] K. Schindler, C.E. Elger, K. Lehnertz, Increasing synchronization may promote seizure termination: Evidence from status epilepticus, Clin. Neurophysiol. 118 
(2007) 1955-1968. doi:10.1016/j.clinph.2007.06.006.

[23] M.A. Kramer, W. Truccolo, U.T. Eden, K.Q. Lepage, L.R. Hochberg, E.N. Eskandar, J.R. Madsen, J.W. Lee, A. Maheshwari, E. Halgren, C.J. Chu, S.S. Cash, Human seizures self-terminate across spatial scales via a critical transition., Proc. Natl. Acad. Sci. U. S. A. 109 (2012) 21116-21. doi:10.1073/pnas.1210047110.

[24] J. Engel, B.I. Ludwig, M. Fetell, Prolonged partial complex status epilepticus: EEG and behavioral observations., Neurology. 28 (1978) 863-9.

[25] N.E. Hamil, H.R. Cock, M.C. Walker, Acute down-regulation of adenosine A(1) receptor activity in status epilepticus., Epilepsia. 53 (2012) 177-88. doi:10.1111/j.1528-1167.2011.03340.x.

[26] A.M. Mazarati, C.G. Wasterlain, R. Sankar, D. Shin, Self-sustaining status epilepticus after brief electrical stimulation of the perforant path., Brain Res. 801 (1998) 251-3.

[27] A. Khalil, S. Kovac, G. Morris, M.C. Walker, Carvacrol after status epilepticus (SE) prevents recurrent SE, early seizures, cell death and cognitive decline, Epilepsia. (2017) in press

[28] S. Shinnar, A.T. Berg, S.L. Moshe, R. Shinnar, How long do new-onset seizures in children last?, Ann. Neurol. 49 (2001) 659-64.

[29] S. Shinnar, D.C. Hesdorffer, D.R. Nordli, J.M. Pellock, C. O’Dell, D. V Lewis, L.M. Frank, S.L. Moshé, L.G. Epstein, A. Marmarou, E. Bagiella, FEBSTAT Study Team, Phenomenology of prolonged febrile seizures: results of the FEBSTAT study., Neurology. 71 (2008) 170-6. doi:10.1212/01.wnl.0000310774.01185.97.

[30] R.J. DeLorenzo, L.K. Garnett, A.R. Towne, E.J. Waterhouse, J.G. Boggs, L. Morton, M.A. Choudhry, T. Barnes, D. Ko, Comparison of status epilepticus with prolonged seizure episodes lasting from 10 to 29 minutes., Epilepsia. 40 (1999) 164-9.

[31] S. Shorvon, M. Ferlisi, The treatment of super-refractory status epilepticus: a critical review of available therapies and a clinical treatment protocol., Brain. 134 (2011) 2802-18. doi:10.1093/brain/awr215.

[32] R. Jaitly, J.A. Sgro, A.R. Towne, D. Ko, R.J. DeLorenzo, Prognostic value of EEG monitoring after status epilepticus: a prospective adult study., J. Clin. Neurophysiol. 14 (1997) 326-34. http://www.ncbi.nlm.nih.gov/pubmed/9337142 (accessed October 15, 2015).

[33] A.M. Mazarati, R.A. Baldwin, R. Sankar, C.G. Wasterlain, Time-dependent decrease in the effectiveness of antiepileptic drugs during the course of self- 
sustaining status epilepticus., Brain Res. 814 (1998) 179-85.

[34] N.C. Wang, L.B. Good, S.T. Marsh, D.M. Treiman, EEG stages predict treatment response in experimental status epilepticus., Epilepsia. 50 (2009) 949-52.

[35] J. Kapur, R.L. Macdonald, Rapid seizure-induced reduction of benzodiazepine and $\mathrm{Zn2+}$ sensitivity of hippocampal dentate granule cell GABAA receptors., J. Neurosci. 17 (1997) 7532-40.

[36] H.P. Goodkin, S. Joshi, Z. Mtchedlishvili, J. Brar, J. Kapur, Subunit-specific trafficking of $\operatorname{GABA}(\mathrm{A})$ receptors during status epilepticus., J. Neurosci. 28 (2008) 2527-38. doi:10.1523/JNEUROSCI.3426-07.2008.

[37] D.E. Naylor, H. Liu, C.G. Wasterlain, Trafficking of GABA(A) receptors, loss of inhibition, and a mechanism for pharmacoresistance in status epilepticus., J. Neurosci. 25 (2005) 7724-33. doi:10.1523/JNEUROSCI.4944-04.2005.

[38] R. Eckel, B. Szulc, M.C. Walker, J.T. Kittler, Activation of calcineurin underlies altered trafficking of $\alpha 2$ subunit containing GABAA receptors during prolonged epileptiform activity., Neuropharmacology. 88 (2015) 82-90. doi:10.1016/j.neuropharm.2014.09.014.

[39] S. Joshi, K. Rajasekaran, K.M. Hawk, J. Brar, B.M. Ross, C.A. Tran, S.J. Chester, H.P. Goodkin, Phosphatase inhibition prevents the activity-dependent trafficking of GABAA receptors during status epilepticus in the young animal., Epilepsia. 56 (2015) 1355-65. doi:10.1111/epi.13098.

[40] A.C. Rice, R.J. DeLorenzo, N-methyl-D-aspartate receptor activation regulates refractoriness of status epilepticus to diazepam., Neuroscience. 93 (1999) 117-23.

[41] B.S. Martin, J. Kapur, A combination of ketamine and diazepam synergistically controls refractory status epilepticus induced by cholinergic stimulation., Epilepsia. 49 (2008) 248-55. doi:10.1111/j.1528-1167.2007.01384.x.

[42] N.Y. Walton, D.M. Treiman, Motor and electroencephalographic response of refractory experimental status epilepticus in rats to treatment with MK-801, diazepam, or MK-801 plus diazepam., Brain Res. 553 (1991) 97-104.

[43] B.A. Orser, K.J. Canning, J.F. Macdonald, Mechanisms of general anesthesia., Curr. Opin. Anaesthesiol. 15 (2002) 427-33.

[44] M.A. Rogawski, C.M. Loya, K. Reddy, D. Zolkowska, C. Lossin, Neuroactive steroids for the treatment of status epilepticus., Epilepsia. 54 Suppl 6 (2013) 93-8. doi:10.1111/epi.12289.

[45] M. Holtkamp, X. Tong, M.C. Walker, Propofol in subanesthetic doses terminates status epilepticus in a rodent model., Ann. Neurol. 49 (2001) 260- 
3. http://www.ncbi.nlm.nih.gov/pubmed/11220748 (accessed July 1, 2012).

[46] L. Silayeva, T.Z. Deeb, R.M. Hines, M.R. Kelley, M.B. Munoz, H.H.C. Lee, N.J. Brandon, J. Dunlop, J. Maguire, P.A. Davies, S.J. Moss, KCC2 activity is critical in limiting the onset and severity of status epilepticus., Proc. Natl. Acad. Sci. U. S. A. 112 (2015) 3523-8. doi:10.1073/pnas.1415126112.

[47] D.E. Naylor, H. Liu, J. Niquet, C.G. Wasterlain, Rapid surface accumulation of NMDA receptors increases glutamatergic excitation during status epilepticus., Neurobiol. Dis. 54 (2013) 225-38. doi:10.1016/j.nbd.2012.12.015.

[48] K. Rajasekaran, M. Todorovic, J. Kapur, Calcium-permeable AMPA receptors are expressed in a rodent model of status epilepticus., Ann. Neurol. 72 (2012) 91-102. doi:10.1002/ana.23570.

[49] K.E. Chandler, A.P. Princivalle, R. Fabian-Fine, N.G. Bowery, D.M. Kullmann, M.C. Walker, Plasticity of GABA(B) receptor-mediated heterosynaptic interactions at mossy fibers after status epilepticus., J. Neurosci. 23 (2003) 11382-91.

[50] H.A. Volk, W. Löscher, Multidrug resistance in epilepsy: Rats with drugresistant seizures exhibit enhanced brain expression of P-glycoprotein compared with rats with drug-responsive seizures, Brain. 128 (2005) 13581368. doi:10.1093/brain/awh437.

[51] M. Bankstahl, S. Klein, K. Römermann, W. Löscher, Knockout of Pglycoprotein does not alter antiepileptic drug efficacy in the intrahippocampal kainate model of mesial temporal lobe epilepsy in mice., Neuropharmacology. 109 (2016) 183-95. doi:10.1016/j.neuropharm.2016.06.007.

[52] G.M. McKhann, H.J. Wenzel, C.A. Robbins, A.A. Sosunov, P.A. Schwartzkroin, Mouse strain differences in kainic acid sensitivity, seizure behavior, mortality, and hippocampal pathology., Neuroscience. 122 (2003) 551-61.

[53] L. Covolan, L.E. Mello, Temporal profile of neuronal injury following pilocarpine or kainic acid-induced status epilepticus., Epilepsy Res. 39 (2000) 133-52.

[54] R.S. Sloviter, C.A. Zappone, B.D. Harvey, A. V Bumanglag, R.A. Bender, M. Frotscher, \&quot;Dormant basket cell\&quot; hypothesis revisited: relative vulnerabilities of dentate gyrus mossy cells and inhibitory interneurons after hippocampal status epilepticus in the rat., J. Comp. Neurol. 459 (2003) 44-76. doi:10.1002/cne.10630.

[55] B.S. Meldrum, R.W. Horton, Physiology of status epilepticus in primates., Arch. Neurol. 28 (1973) 1-9.

[56] B.S. Meldrum, J.B. Brierley, Prolonged epileptic seizures in primates. Ischemic 
cell change and its relation to ictal physiological events., Arch. Neurol. 28 (1973) 10-7.

[57] T. Griffiths, M.C. Evans, B.S. Meldrum, Intracellular calcium accumulation in rat hippocampus during seizures induced by bicuculline orl-allylglycine, Neuroscience. 10 (1983) 385-395. doi:10.1016/0306-4522(83)90141-0.

[58] L.S. Deshpande, J.K. Lou, A. Mian, R.E. Blair, S. Sombati, E. Attkisson, R.J. DeLorenzo, Time course and mechanism of hippocampal neuronal death in an in vitro model of status epilepticus: role of NMDA receptor activation and NMDA dependent calcium entry., Eur. J. Pharmacol. 583 (2008) 73-83. doi:10.1016/j.ejphar.2008.01.025.

[59] A.E. Abele, K.P. Scholz, W.K. Scholz, R.J. Miller, Excitotoxicity induced by enhanced excitatory neurotransmission in cultured hippocampal pyramidal neurons, Neuron. 4 (1990) 413-419. doi:10.1016/0896-6273(90)90053-I.

[60] S. Kovac, A.-M. Domijan, M.C. Walker, A.Y. Abramov, Prolonged seizure activity impairs mitochondrial bioenergetics and induces cell death., J. Cell Sci. 125 (2012) 1796-806. doi:10.1242/jcs.099176.

[61] D.G. Fujikawa, A.H. Daniels, J.S. Kim, The competitive NMDA receptor antagonist CGP 40116 protects against status epilepticus-induced neuronal damage., Epilepsy Res. 17 (1994) 207-19. http://www.ncbi.nlm.nih.gov/pubmed/7912191 (accessed February 24, 2015).

[62] C. Brandt, H. Potschka, W. Löscher, U. Ebert, N-methyl-D-aspartate receptor blockade after status epilepticus protects against limbic brain damage but not against epilepsy in the kainate model of temporal lobe epilepsy., Neuroscience. 118 (2003) 727-40. http://www.ncbi.nlm.nih.gov/pubmed/12710980 (accessed February 24, 2015).

[63] D.C. Henshall, M. Diaz-Hernandez, M.T. Miras-Portugal, T. Engel, P2X receptors as targets for the treatment of status epilepticus., Front. Cell. Neurosci. 7 (2013) 237. doi:10.3389/fncel.2013.00237.

[64] D.C. Henshall, J. Chen, R.P. Simon, Involvement of caspase-3-like protease in the mechanism of cell death following focally evoked limbic seizures., J. Neurochem. 74 (2000) 1215-23.

[65] D.G. Fujikawa, X. Ke, R.B. Trinidad, S.S. Shinmei, A. Wu, Caspase-3 is not activated in seizure-induced neuronal necrosis with internucleosomal DNA cleavage., J. Neurochem. 83 (2002) 229-40.

[66] S. Narkilahti, T.J. Pirttilä, K. Lukasiuk, J. Tuunanen, A. Pitkänen, Expression and activation of caspase 3 following status epilepticus in the rat., Eur. J. Neurosci. 18 (2003) 1486-96. http://www.ncbi.nlm.nih.gov/pubmed/14511328 
(accessed February 24, 2015).

[67] I.M. Araújo, J.M. Gil, B.P. Carreira, P. Mohapel, A. Petersen, P.S. Pinheiro, D. Soulet, B.A. Bahr, P. Brundin, C.M. Carvalho, Calpain activation is involved in early caspase-independent neurodegeneration in the hippocampus following status epilepticus., J. Neurochem. 105 (2008) 666-76. doi:10.1111/j.14714159.2007.05181.x.

[68] M. Baudry, X. Bi, Calpain-1 and Calpain-2: The Yin and Yang of Synaptic Plasticity and Neurodegeneration., Trends Neurosci. 39 (2016) 235-45. doi:10.1016/j.tins.2016.01.007.

[69] J. Seinfeld, N. Baudry, X. Xu, X. Bi, M. Baudry, Differential Activation of Calpain-1 and Calpain-2 following Kainate-Induced Seizure Activity in Rats and Mice, eNeuro. 3 (2016). doi:10.1523/ENEURO.0088-15.2016.

[70] U. Förstermann, W.C. Sessa, Nitric oxide synthases: regulation and function., Eur. Heart J. 33 (2012) 829-37, 837a-837d. doi:10.1093/eurheartj/ehr304.

[71] S. Puttachary, S. Sharma, S. Verma, Y. Yang, M. Putra, A. Thippeswamy, D. Luo, T. Thippeswamy, 1400W, a highly selective inducible nitric oxide synthase inhibitor is a potential disease modifier in the rat kainate model of temporal lobe epilepsy, Neurobiol. Dis. 93 (2016) 184-200. doi:10.1016/j.nbd.2016.05.013.

[72] C. Szabó, H. Ischiropoulos, R. Radi, Peroxynitrite: biochemistry, pathophysiology and development of therapeutics., Nat. Rev. Drug Discov. 6 (2007) 662-80. doi:10.1038/nrd2222.

[73] S. Moncada, J.P. Bolaños, Nitric oxide, cell bioenergetics and neurodegeneration., J. Neurochem. 97 (2006) 1676-89. doi:10.1111/j.14714159.2006.03988.x.

[74] Y. Mikami, K. Kanemaru, Y. Okubo, T. Nakaune, J. Suzuki, K. Shibata, H. Sugiyama, R. Koyama, T. Murayama, A. Ito, T. Yamazawa, Y. Ikegaya, T. Sakurai, N. Saito, S. Kakizawa, M. lino, Nitric Oxide-induced Activation of the Type 1 Ryanodine Receptor Is Critical for Epileptic Seizure-induced Neuronal Cell Death., EBioMedicine. 11 (2016) 253-261. doi:10.1016/j.ebiom.2016.08.020.

[75] R. Abeti, A.Y. Abramov, Mitochondrial Ca2+ in neurodegenerative disorders, Pharmacol. Res. 99 (2015) 377-381. doi:10.1016/j.phrs.2015.05.007.

[76] S. Kovac, A.Y. Abramov, M.C. Walker, Energy depletion in seizures: anaplerosis as a strategy for future therapies., Neuropharmacology. 69 (2013) 96-104. doi:10.1016/j.neuropharm.2012.05.012.

[77] P. Bernardi, A. Rasola, M. Forte, G. Lippe, The Mitochondrial Permeability 
Transition Pore: Channel Formation by F-ATP Synthase, Integration in Signal Transduction, and Role in Pathophysiology., Physiol. Rev. 95 (2015) 1111-55. doi:10.1152/physrev.00001.2015.

[78] C. Camello-Almaraz, P.J. Gomez-Pinilla, M.J. Pozo, P.J. Camello, Mitochondrial reactive oxygen species and Ca2+ signaling., Am. J. Physiol. Cell Physiol. 291 (2006) C1082-8. doi:10.1152/ajpcell.00217.2006.

[79] R. Kovács, S. Schuchmann, S. Gabriel, O. Kann, J. Kardos, U. Heinemann, Free radical-mediated cell damage after experimental status epilepticus in hippocampal slice cultures., J. Neurophysiol. 88 (2002) 2909-18. doi:10.1152/jn.00149.2002.

[80] S. Kovac, A.-M. Domijan, M.C. Walker, A.Y. Abramov, Seizure activity results in calcium- and mitochondria-independent ROS production via NADPH and xanthine oxidase activation., Cell Death Dis. 5 (2014) e1442. doi:10.1038/cddis.2014.390.

[81] M. Patel, Q.-Y. Li, L.-Y. Chang, J. Crapo, L.-P. Liang, Activation of NADPH oxidase and extracellular superoxide production in seizure-induced hippocampal damage., J. Neurochem. 92 (2005) 123-31. doi:10.1111/j.14714159.2004.02838.x.

[82] J.H. Kim, B.G. Jang, B.Y. Choi, H.S. Kim, M. Sohn, T.N. Chung, H.C. Choi, H.K. Song, S.W. Suh, Post-treatment of an NADPH oxidase inhibitor prevents seizure-induced neuronal death, Brain Res. 1499 (2013) 163-172. doi:10.1016/j.brainres.2013.01.007.

[83] S. Williams, N. Hamil, A.Y. Abramov, M.C. Walker, S. Kovac, Status epilepticus results in persistent overproduction of reactive oxygen species, inhibition of which is neuroprotective., Neuroscience. 303 (2015) 160-5. doi:10.1016/j.neuroscience.2015.07.005.

[84] R.R.F. Pestana, E.R. Kinjo, M.S. Hernandes, L.R.G. Britto, Reactive oxygen species generated by NADPH oxidase are involved in neurodegeneration in the pilocarpine model of temporal lobe epilepsy., Neurosci. Lett. 484 (2010) 187-91. doi:10.1016/j.neulet.2010.08.049.

[85] S. Rowley, L.-P. Liang, R. Fulton, T. Shimizu, B. Day, M. Patel, Mitochondrial respiration deficits driven by reactive oxygen species in experimental temporal lobe epilepsy., Neurobiol. Dis. 75 (2015) 151-8. doi:10.1016/j.nbd.2014.12.025.

[86] K. Ryan, D.S. Backos, P. Reigan, M. Patel, Post-translational oxidative modification and inactivation of mitochondrial complex I in epileptogenesis., J. Neurosci. 32 (2012) 11250-8. doi:10.1523/JNEUROSCI.0907-12.2012. 
[87] J.-E. Kim, Y.-J. Kim, J.Y. Kim, T.-C. Kang, PARP1 activation/expression modulates regional-specific neuronal and glial responses to seizure in a hemodynamic-independent manner., Cell Death Dis. 5 (2014) e1362. doi:10.1038/cddis.2014.331. 


\section{Figure legends}

Figure 1: Causes of status epilepticus in children and adults. CVA = cerebrovascular accident, CNS inf = CNS infection, Low AEDs = low antiepileptic drug levels in someone with epilepsy, Drug OD = drug overdose, $\mathrm{EtOH}=$ alcohol related, Remote $=$ remote symptomatic. After ref [14]

Figure 2: Seizure termination is due to a critical transition. (A) There is an ictal state with high variance over short time windows $(50 \mathrm{~ms})$ and a post-ictal state with low variance. The transition from ictal to post-ictal involves flickering (periods of high alternating with low variance). (B) The proportion of different variance in ictal, postictal and flickering periods. (C) Mid-seizure, there is predominantly high variance during the seizure period. During transition the variance distribution is split between pre-ictal, ictal and post-ictal states. (D) Graphic illustration of the stable ictal period, inhibitory mechanisms move the ball to the transition state and then into the stable post-ictal state. (E) Status epilepticus occurs when there is insufficient inhibition or drivers pushing the ball into the ictal state, so that the transition point may be approached but not crossed. (F) Refractory status epilepticus is either because there is a persistent driver into the ictal state (eg persistent etiology) or the landscape (neuronal network) has changed so that a stable post-ictal state no longer exists. Panels A-C are reproduced from ref [23] with permission

Figure 3: The longer in vivo perforant path stimulation continues the greater the number of animals going into self-sustained status epilepticus (SE). After ref [25]

Figure 4: Putative mechanisms leading to neuronal death following calcium (and sodium) entry through NMDA receptors. NMDA receptor activation and calcium entry activate several enzymes including calpains, NADPH oxidase (NOX) and N nitric oxide synthase (NOS). Reactive oxygen species and nitric oxide form peroxynitrite, which is toxic to DNA, proteins and lipids. Calcium from the cytosol is taken up by mitochondria and excessive mitochondria load results in decreased ATP production, energy failure and failure to maintain cellular ionic gradients. Mitochondrial calcium accumulation and reactive oxygen species contribute to the formation of the mitochondrial permeability transition pore (mPTP), which further disrupts mitochondrial function, but also permit cytochrome $c$ into the cytosol where it can activate apoptotic pathways. 